\title{
Stability of Soil and Biosolid Nanocolloid and Macrocolloid Particles in the Absence and Presence of Arsenic, Selenium, Copper and Lead
}

\author{
Jessique Ghezzi, Anastasios Karathanasis, Chris Matocha, Jason Unrine, Yvonne Thompson \\ Department of Plant and Soil Sciences, University of Kentucky, Lexington, KY, USA \\ Email: akaratha@uky.edu
}

Received 26 May 2014; revised 28 June 2014; accepted 5 July 2014

Copyright $@ 2014$ by authors and Scientific Research Publishing Inc. This work is licensed under the Creative Commons Attribution International License (CC BY). http://creativecommons.org/licenses/by/4.0/

(c) (i) Open Access

\begin{abstract}
Due to their enhanced stability and contaminant transport potential, environmental nanoparticles derived from soil and biosolid materials may pose a considerable risk to groundwater quality. Very little information exists on the stability and transportability of environmental or natural nanocolloids in the presence of $\mathrm{As}, \mathrm{Se}, \mathrm{Pb}$ and $\mathrm{Cu}$ contaminants, all of which are considered to represent substantial threats to human and animal populations through groundwater contamination. This study involved stability settling experiments of nanocolloids (NCs) $(<100 \mathrm{~nm})$ and macrocolloids (MCs) (100 - $2000 \mathrm{~nm})$ fractionated from Bt horizons of three Kentucky soils and one biosolid waste material in water suspensions of 0,2 , and $10 \mathrm{mg} \cdot \mathrm{L}^{-1}$ of $\mathrm{As}, \mathrm{Se}, \mathrm{Pb}$ and $\mathrm{Cu}$. The results indicated greater stability in the mineral than the biosolid colloid fractions, and enhanced stability of NCs over corresponding MCs in the presence or absence of contaminants at low contaminant loads. At high contaminant loads nearly all colloids were unstable except for the bio-nanocolloids which still sustained considerable stability. At low contaminant loads, the MC fraction stability sequence was smectitic $>$ mixed $>$ kaolinitic $>$ biosolid. Among the nano-fractions, the smectitic and kaolinitic colloids demonstrated lower stability than the MCs, but higher than those of the mixed and biosolid fractions. Physicochemical characterizations indicated that extensive organic carbon surface coatings and higher $\mathrm{Al} / \mathrm{Fe}: \mathrm{Si}$ ratios may have induced higher stability in the $\mathrm{NC}$ fractions, but their overall stability may also have been hindered in some cases by nano-aggregation phenomena.
\end{abstract}

\section{Keywords}

Nanocolloids, Macrocolloids, Colloid Stability, Contaminant Transport, Nanoparticles

How to cite this paper: Ghezzi, J., Karathanasis, A., Matocha, C., Unrine, J. and Thompson, Y. (2014) Stability of Soil and Biosolid Nanocolloid and Macrocolloid Particles in the Absence and Presence of Arsenic, Selenium, Copper and Lead. Open Journal of Soil Science, 4, 246-258. http://dx.doi.org/10.4236/ojss.2014.47027 


\section{Introduction}

Water dispersed colloids (WDC) are known to disperse from soil aggregates and remain mobile in subsurface environments [1] [2]. They have average diameters between 1 and $1000 \mathrm{~nm}$, which includes nanoparticles, with one dimension equal to or less than $100 \mathrm{~nm}$ [3]-[5]. These naturally derived NCs are prevalent in the environment and play various roles in environmental processes such as the cycling of nutrients, remediation procedures, contaminant transport and soil genesis [6].

Nanoparticle stability can be used as an indicator of potential transport into groundwater supplies. The tendency for particles to aggregate or remain stable in solution may be affected by the complex mineralogical and physico-chemical attributes of the particle, including particle size, surface chemistry, and the aqueous environment surrounding transport [5] [6]. Even though the small size of nanoparticles may promote long-range stability and transport due to the proportionality of their displacement to the inverse square root of their radius, their high surface energy may also result in multiple interparticle collisions and aggregation, especially at increased ionic strengths [6] [7]. Chemically, colloid stability can be influenced by solution ionic strength and composition, particle surface coatings and functional groups, $\mathrm{pH}$, and zeta potential [6] [8]. Stability can also be a function of the mineralogical composition of the particles. Studies have shown that kaolinitic particles tend to flocculate, while smectitic particles tend to remain dispersed or stable over time [1] [9]. An important consideration in natural systems includes their complex composition, which consists of mixed colloidal phases. This encompasses the interactions with other NCs and solutes in the system, particularly since nanoparticle mobility is controlled mainly by Brownian motion and not by gravitational settling like their larger counterparts [10].

Nanoparticles and NCs can carry contaminants, illustrating their potential role in environmental pollution, water quality, and remediation processes [11] [12]. Four contaminants that are of particular concern include arsenic (As), selenium (Se), copper $(\mathrm{Cu})$, and lead $(\mathrm{Pb})$, all of which are considered toxic to humans, wildlife and plants at relatively high concentrations. All four of these contaminants are accumulated in the environment from anthropogenic sources/industrial runoff, including car batteries, where arsenic is used to strengthen copper and lead alloys [13], or from naturally occurring sources like seleniferous and arsenopyrite-derived soils [14] [15]. They may be readily transported into groundwater by naturally occurring soil and biosolid colloids. While studies have characterized, modeled, and predicted the movement of water dispersible colloids [1] [11] [16] [17], there is a lack of information comparing the stability of macro-sized $(0.1-2.0 \mu \mathrm{m})$ to nano-sized colloids ( $<0.1$ $\mu \mathrm{m}$ ) of differing mineralogy from subsurface horizons, and their potential to transport contaminants such as Se, $\mathrm{As}, \mathrm{Cu}$, and $\mathrm{Pb}$. Additionally, there is little to no information available on the role of nano-sized biosolid-derived colloids, despite studies showing that larger sized bio-colloids enhance contaminant transport through soil [18]-[20].

The objectives of this study were to evaluate and compare the stability of water suspended NCs and MCs derived from Bt horizons of 3 Kentucky soils with kaolinitic, montmorillonitic, and mixed mineralogies, as well as from an aerobically digested biosolid with three levels of $\mathrm{Cu}, \mathrm{Pb}$, As, and Se contaminant loads.

\section{Methods and Materials}

Mineral colloids were fractionated from the Bt horizons of three Kentucky soils with differing mineralogy: Caleast-variant (fine, smectitic, mesic mollic Hapludalf), Tilsit (fine-silty, mixed, mesic Typic Fragiudult), and Trimble (fine-loamy, siliceous, mesic Typic Paleudult). The recovered colloids are referred to as smectitic, mixed, and kaolinitic NCs or MCs, respectively. An aerobically digested municipal sewage sludge, obtained from Jessamine County, Kentucky, was fractionated to obtain the biosolid NCs and MCs. Centrifugation was used to fractionate the WDCs into two size classes (NCs < $100 \mathrm{~nm}$ and MCs $100-2000 \mathrm{~nm}$ ) using a Centra GP8R Model 120 centrifuge (ThermoIEC) in deionized water (resistivity of $1 \mu \Omega \mathrm{cm}$ at $25^{\circ} \mathrm{C}$ ). The clay fraction was separated from the bulk soil using centrifugation at 107 RCF for 3.5 minutes, and then at 4387 RCF for 46 minutes to separate the NCs from the MCs [6]. Centrifugation times were determined using Stokes law, and separation of the NC from MC fraction was performed on a centrifuge with a rotor radius of $170 \mathrm{~mm}$, a speed of $4387 \mathrm{RCF}$, a density difference from water of $1650 \mathrm{~kg} \cdot \mathrm{m}^{-3}$, and viscosity of 0.0008904 Pas. All collected sample suspensions were then diluted to $50 \mathrm{mg} \cdot \mathrm{L}^{-1}$ concentrations for additional analysis.

\subsection{Stability Experiments}

Settling kinetics experiments were used to determine the stability of the NCs and MCs over time. Duplicate 400 
$\mathrm{mL}$ suspensions of $50 \mathrm{mg}$ colloid $\cdot \mathrm{L}^{-1}$ in de-ionized water $\left(\mathrm{D}-\mathrm{H}_{2} \mathrm{O}\right)$ were used to generate stability graphs based on sampled concentrations at times 0,30 minutes, 1, 2, 4, 8, 24 and 48 hours. Additional stability experiments were performed using the same procedure with the addition of 2 and $10 \mathrm{mg} \cdot \mathrm{L}^{-1}$ mixed contaminant concentrations of $\mathrm{Pb}, \mathrm{Cu}, \mathrm{As}$, and Se [prepared as aqueous solutions from: $\mathrm{PbCl}_{2}$ (98\% purity, Aldrich Chemicals, Milwaukee, WI), $\mathrm{CuCl}_{2}\left(>99 \%\right.$ purity, Sigma Chemical Company, St. Louis, MO), arsenic acid $\mathrm{Na}_{2} \mathrm{HAsO}_{4} \cdot 7 \mathrm{H}_{2} \mathrm{O}$ (98\% purity, Sigma Chemical Company, St. Louis, MO), and sodium selenate decahydrate $\mathrm{Na}_{2} \mathrm{SeO}_{4} \cdot 10 \mathrm{H}_{2} \mathrm{O}$ (99.9\% purity, Sigma Chemical Company, St. Louis, MO)]. The suspended colloid concentrations were determined using a colorimetric procedure on a Molecular Devices Versa Max Microplate Reader at $450 \mathrm{~nm}$ [2] [20].

\subsection{Particle Size, Morphology, and Surface Area Analysis}

Primary particle size of NC particles was determined using a high resolution transmission electron microscope (JEOL 2010F) attached to an Oxford EDS detector (TEM-EDS; JEOL 2010F, Tokyo, Japan) [21] [22]. Primary particle size of MC particles was determined using a S-4300 scanning electron microscope, equipped with a Princeton Gamma-Tech EDS Microanalysis system (SEM-EDS; Hitachi S-4300, Tokyo, Japan) [23]. The average diameters were calculated using ImageJ software (ImageJ 1.46r, Wayne Rasband, National Institutes of Health, USA). A Malvern Instruments ZetasizerNano ZS (Malvern, United Kingdom) was used to obtain intensity weighted mean particle hydrodynamic diameters (z-average diameter, $\mathrm{d}_{\mathrm{h}}$ ) on suspensions of $50 \mathrm{mg}$ colloid $\cdot \mathrm{L}^{-1}$ using dynamic light scattering $\left(173^{\circ}\right.$ backscatter analysis method). This procedure also allowed estimates of NC and MC aggregation potentials in the absence and presence of $2 \mathrm{mg} \cdot \mathrm{L}^{-1}$ additions of $\mathrm{As}, \mathrm{Cu}, \mathrm{Pb}$ and Se contaminants. Surface area analysis was performed on both the NCs and MCs using the Ethylene Glycol Monoethyl Ether (EGME) method.

\subsection{Mineralogical Characterization}

A combination of X-ray diffraction (XRD) and Thermogravimetric analysis (TG) was employed for mineralogical characterization. For XRD analysis, K, K-heat treated, Mg, and Mg-glycol saturated samples were collected on glass slides and analyzed on a Phillips PW 1840 diffractometer and PW 1729 X-ray generator (Mahwah, NJ) fitted with a cobalt X-ray tube and run at $40 \mathrm{kV}$ and $30 \mathrm{~mA}$ using a Bragg-Bretano design goniometer at a scanning rate of $0.05^{\circ} 2 \theta$ per minute from $2^{\circ}$ to $40^{\circ}$ with a scattering slit of $0.1^{\circ}$. Mg-saturated colloids were also used for TG analysis on a Thermal Analyst 2000 (TA Instruments) equipped with a 951 Thermogravimetric Analyzer (DuPont Instruments) with a heating rate of $20^{\circ} \mathrm{C} / \mathrm{min}$ under $\mathrm{N}_{2}$ atmosphere [24]. The TG Analysis was used to verify the presence of kaolinite, as well as goethite and gibbsite, and to compliment quantification interpretations derived from the XRD patterns [24].

\subsection{Chemical Characterization}

A Denver Instruments Model $250 \mathrm{pH}^{*}$ ISE* electrical conductivity meter (Arvada, CO) was used to measure $\mathrm{pH}$ and electrical conductivity (EC) of the NC and MC suspensions. Ionic strength (IS) was derived by multiplying electrical conductivities by 0.0127 [25]. A Varian Spectr AA 50B atomic absorption spectrometer was used to determine the base cation concentrations $\left(\mathrm{Ca}^{2+}, \mathrm{Mg}^{2+}, \mathrm{K}^{+}\right.$, and $\left.\mathrm{Na}^{+}\right)$, which were summed and used to report the cation exchange capacity (CEC) from triplicate samples of the NCs and MCs using an adapted version of the ammonium acetate method. Concentrations of $\mathrm{Ca}^{2+}, \mathrm{Mg}^{2+}$, and $\mathrm{Na}^{+}$were used to calculate sodium adsorption ratios (SAR). A Flash EA 1112 Series Soil Analyzer (Thermo Electron Corporation) with a Mettler Toledo MX5 microbalance was used to determine organic carbon (OC). Zeta potential measurements in absence of contaminants were used to estimate surface and point of zero charge (PZC), as well as suspension stability at adjusted $\mathrm{pH}$ values of 4, 6, 8 and 10 using $0.01 \mathrm{~N} \mathrm{HCl}$ and $\mathrm{NaOH}$. The Smoluchowski approximations determined zeta potentials from electrophoretic mobilities on suspensions in $0.001 \mathrm{M} \mathrm{NaCl}$ background electrolyte as measured on a Malvern Zetasizer Nano ZS (Malvern, United Kingdom). Additionally, zeta potentials were measured in the presence of 2 and $10 \mathrm{mg} \cdot \mathrm{L}^{-1}$ additions of $\mathrm{Cu}, \mathrm{Pb}$, As and Se.

\subsection{Statistical Analysis}

The accepted error levels for all duplicate and triplicate measurements were $\leq 15 \%$. Significance of differences between means was tested using Analysis of Variance (ANOVA) (SAS PROC GLM) and Fisher's protected 
least significant difference test (LSD) in SAS 9.3 (SAS Institute Inc., Cary, NC, USA). The statistical significance level used was $\alpha=0.05$.

\section{Results and Discussion}

\subsection{Colloid Stability}

\subsubsection{Effect of Particle Size}

Primary particle size analysis by scanning electron microscopy (SEM) indicated size ranges between 288 and $549 \mathrm{~nm}$ for the MCs, while transmission electron microscopy (TEM) portrayed size ranges between 7 and $50 \mathrm{~nm}$ for the NCs (Table 1). Stability settling characteristics of the colloid suspensions as affected by size and contaminant load are shown in Figure 1 and Table 2. A particle is considered stabile if it tends to remain dispersed in solution [2]. Based on size alone, the settling experiments showed NCs to be significantly more stable in suspension $(\alpha=0.05)$ after 48 hours than the MCs in the presence and absence of contaminants (Figure 1). After 48 hours, in the absence of contaminants mineral MCs had an average of $80 \%$ colloids in suspension while NCs had an average of $96 \%$ (Table 2). In comparison, the bio-MCs and bio-NCs had 36\% and 58\%, respectively (Table 2). This highlights two things: first, the enhanced mobility and contaminant transport potential of the NCs over their corresponding MCs, and second, the greater stability of the mineral colloids over the bio-colloids without contaminants present. Upon the addition of $2 \mathrm{mg} / \mathrm{L}$ contaminants, the mineral NCs had an average of 35\% more colloids in suspension than corresponding MCs (65\% versus 30\%, respectively) (Table 2). Despite greater stability in the mineral colloids at $2 \mathrm{mg} / \mathrm{L}$ contaminant additions, the bio-NCs had as much as $18 \%$ colloids in suspension in the presence of $10 \mathrm{mg} / \mathrm{L}$ contaminants, compared to only $1 \%$ on average for the mineral colloids (Table 2) [26] [27].

The average intensity weighted (Z-average) hydrodynamic diameters $\left(\mathrm{d}_{\mathrm{h}}\right)$ can be used to indicate stability as well (Figure 2). Since $d_{h}$ is related to the size of aggregates formed by the colloids, the smaller values would

Table 1. Selected physical and morphological characteristics of the macrocolloid and nanocolloid fractions.

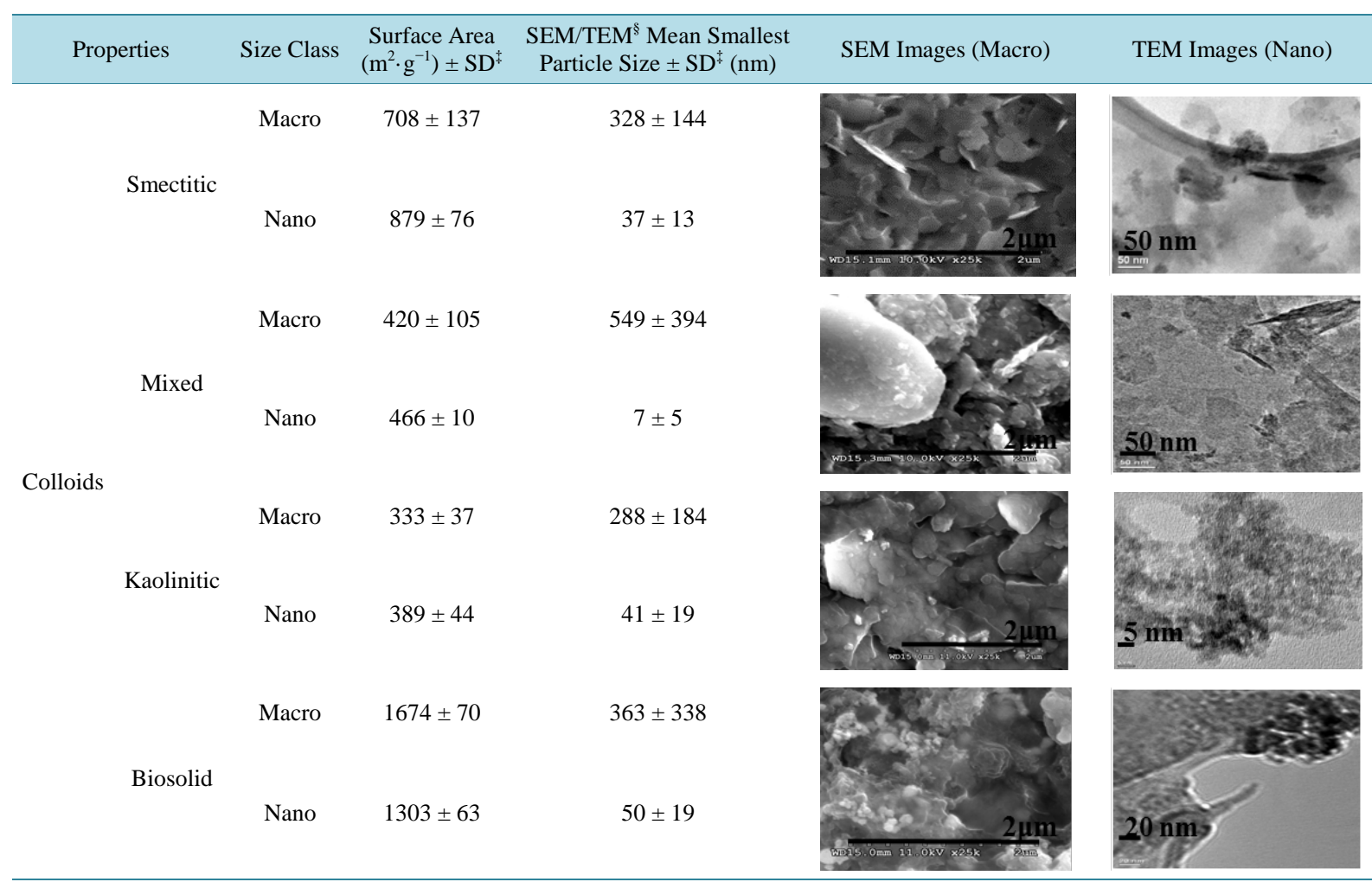

${ }^{\ddagger} \mathrm{SD}=$ Standard Deviation from duplicate or triplicate measurements. ${ }^{\S} \mathrm{SEM}=$ Scanning Electron Microscopy, TEM= Transmission Electron Microscopy data represent the average smallest dimension of 300 representative particles from three to eight images of each size fraction as measured until the average and standard deviation values had less than $10 \%$ variation. 


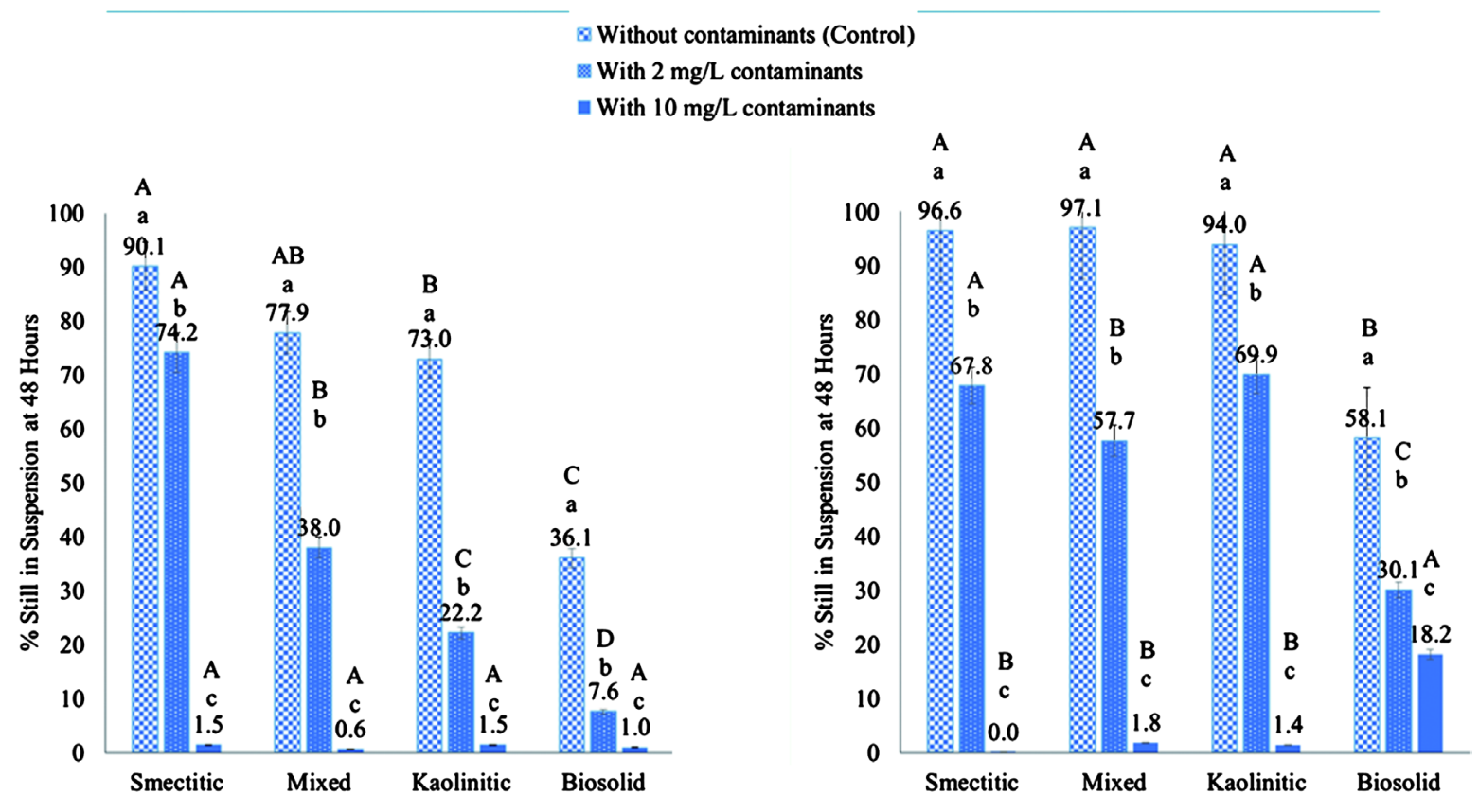

Figure 1. Stability of the macro- and nano-colloids in mixtures of equal parts $\left(0,2\right.$, and $\left.10 \mathrm{mg} \cdot \mathrm{L}^{-1}\right)$ of each contaminant (As, $\mathrm{Se}, \mathrm{Cu}$ and $\mathrm{Pb}$ ) expressed as \% of colloids remaining in suspension after 48 hours (error bars represent standard error of means; upper case letters represent significant differences $(\alpha=0.05)$ between mineralogy at the same level of contaminant concentration; lower case letters represent trends within the same mineralogy across the 0 , 2 , and $10 \mathrm{mg} \cdot \mathrm{L}^{-1} \mathrm{contaminant}$ concentration gradients).

Table 2. Average \% of mineral and biosolid colloids still in suspension at 48 hours.

\begin{tabular}{|c|c|c|c|c|}
\hline \multirow{2}{*}{$\begin{array}{c}\text { Composition: } \\
\text { Size: }\end{array}$} & \multicolumn{2}{|c|}{ Mineral } & \multicolumn{2}{|c|}{ Biosolid } \\
\hline & Macro & Nano & Macro & Nano \\
\hline Without contaminants (Control) & $80 \%$ & $96 \%$ & $36 \%$ & $58 \%$ \\
\hline With 2 mg/L contaminants & $45 \%$ & $65 \%$ & $8 \%$ & $30 \%$ \\
\hline With $10 \mathrm{mg} / \mathrm{L}$ contaminants & $1 \%$ & $1 \%$ & $1 \%$ & $18 \%$ \\
\hline
\end{tabular}
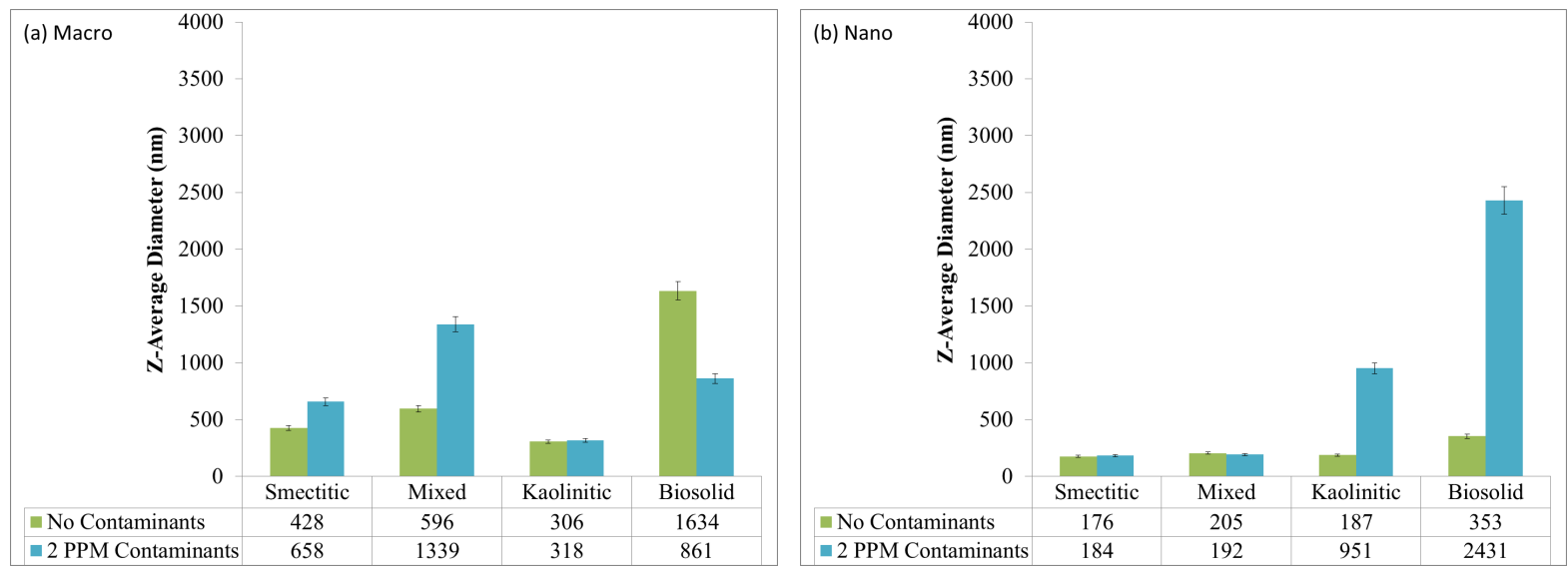

Figure 2. Dynamic Light Scattering (DLS) intensity weighted hydrodynamic diameters $\left(\mathrm{d}_{\mathrm{h}}\right)$ of macrocolloids (a) and nanocolloids (b) in the absence and presence of $2 \mathrm{mg} / \mathrm{L}$ contaminants after a 48 hour interaction (error bars represent standard error of the means). 
indicate smaller aggregate size, thus more dispersive colloids. In the absence of contaminants the $d_{h}$ values complemented the stability trends, indicating greater stability in the mineral NCs over that of the bio-NCs (Figure 1 and Figure 2). For the MCs, the anomaly was the kaolinitic MC fraction, which showed the smallest $\mathrm{d}_{\mathrm{h}}$ (Figure 2), yet in the stability settling experiments (Figure 1) portrayed lower stability than the smectitic and mixed MC fraction. Other than the MC kaolinitic fraction, the smectitic colloids showed consistently small $d_{h}$ values and high stability in the settling studies compared to other colloid compositions (Figure 1 and Figure 2). Since $d_{h}$ also reflects on the size of aggregates formed by the colloids, the smaller values indicate smaller aggregate size thus more dispersive colloids. The $d_{h}$ values in the absence of contaminants suggested that the MCs were nearly four-times larger than the NCs, with an average $d_{h}$ of $842 \mathrm{~nm}$ for the MCs and $224 \mathrm{~nm}$ for the NCs (Figure 2). The $d_{h}$ also showed compositional trends, with mean comparisons showing the bio-colloids to be significantly larger than the mineral colloids $(\alpha=0.05)$. While the larger $d_{h}$ values (as measured by DLS) compared to the crystallite diameters (as measured by TEM/SEM) may indicate some aggregation in both size fractions, the larger DLS size range may also be partially explained by the disproportionate influence of the larger particles on the overall average diameter compared to the smaller particles (Figure 1), or by potential surface coatings on the particles [8] [16].

The $d_{h}$ values of the kaolinitic MCs, the smectitic and mixed NCs were unaffected by the addition of contaminants, but increased significantly for the smectitic MCs, and the kaolinitic, and biosolid NCs. Surprisingly, the biosolid MCs experienced a considerable reduction in size in the presence of contaminants (Figure 2). The higher $d_{h}$ values in the presence of contaminants were probably caused by enhanced aggregation due to increased ionic strength from the addition of polyvalent ions (Figure 2) [8] [16]. MCs showed greater aggregation potentials in the presence of contaminants than NCs through larger shifts in $\mathrm{d}_{\mathrm{h}}$ values, especially in the biosolid and mixed MCs (Figure 2). The largest $\mathrm{d}_{\mathrm{h}}$ shifts with contaminant additions occurred in the kaolinitic and biosolid NCs and the mixed and biosolid MCs (Figure 2). Greater contaminant loading potential of cation contaminants onto larger surface areas could cause aggregation of other negatively charged colloids, thus creating pseudo-aggregates that increase the intensity weighted averages measured (Figure 2) [8] [16]. In spite of a size increase of about $230 \mathrm{~nm}$, the smectitic MC fraction showed a slight reduction in stability comparable to that of the NC fraction. In contrast, the stability of the kaolinitic, mixed, and biosolid MC fraction decreased significantly regardless of the $d_{h}$ size changes (Figure 2) following the mixed $>$ kaolinitic $>$ biosolid trend. The addition of the $2 \mathrm{mg} \cdot \mathrm{L}^{-1}$ contaminant load caused a consistent stability reduction across all NCs following the sequence smectitic $=$ kaolinitic $>$ mixed $>$ biosolid. However, the stability of the NCs was generally higher than that of the MCs under the $2 \mathrm{mg} \cdot \mathrm{L}^{-1}$ contaminant load, with the exception of the smectitic MCs which showed similar stability to the smectitic NCs.

\subsubsection{Effects of Mineralogy}

Mineralogy appears to have played a partial role in the stability processes of the MCs and NCs (Table 3). In the absence of contaminants, the smectitic MCs had greater stability than the kaolinitic and biosolid MCs, but equal stability to the mixed MCs (Figure 1). In the absence of contaminants, the smectitic, mixed and kaolinitic NCs were more stable than the biosolid NCs (Figure 1). After additions of $2 \mathrm{mg} \cdot \mathrm{L}^{-1}$ contaminants the mineral colloids showed more surface repulsion than the biosolid colloids. The smectitic and kaolinitic NCs were more stable than the mixed and biosolid colloids, while within the MC fraction, the smectitic and mixed MCs were more stable than the kaolinitic and biosolid colloids (Figure 1). With the exception of the bio-NCs, the addition of 10 $\mathrm{mg} \cdot \mathrm{L}^{-1}$ contaminants overwhelmed the available surface area of the colloids and induced significant flocculation (Figure 1). The greater stability (Figure 1) of the smectitic colloids over that of other mineralogies is likely due to higher surface charge potential, with the greater charge densities in smaller sized colloids resulting in greater repulsion (Table 1, Figure 1) [1] [28]. Lower stability in colloids containing kaolinite are likely due to the tendency of kaolinite to remain flocculated at $\mathrm{pH}$ less than 7.5 [1] [9]. Additionally, smaller sized fractions that are high in kaolinite, $\mathrm{Al}$ and Fe hydroxides may have enhanced surface charge density contributing to destabilization potentials [2] [8]. This is evidenced by the attachment of smaller nanoparticles to several MC surfaces (Table 1). Additionally, the presence of hydroxy-interlayered vermiculite may have released $\mathrm{Al}$ and promoted flocculation processes in the mixed and kaolinitic colloid fractions (Figure 1 and Figure 2; Table 3) [2]. In the stability kinetics experiments, mixed MCs were more stable than kaolinitic MCs after the addition of $2 \mathrm{mg} \cdot \mathrm{L}^{-1}$, with a reversed stability sequence for the NCs (Figure 1). The mixed NCs were less stable than the kaolinitic NCs in the presence of $2 \mathrm{mg} \cdot \mathrm{L}^{-1}$ contaminants, probably due to their higher Fe-hydroxide content (Figure 1, 
Table 3. Mineralogical composition of nano- and macro-colloid fractions.

\begin{tabular}{ccc}
\hline Macro & Nano & ${ }^{*} \mathrm{~K}_{29}, \mathrm{Ge}_{7}, \mathrm{Gi}_{0}, \mathrm{Q}_{6}, \mathrm{M}_{10}, \mathrm{Sm}_{48}, \mathrm{MVI}_{0}, \mathrm{HIV}_{0}$ \\
& Macro & ${ }^{*} \mathrm{~K}_{30}, \mathrm{Ge}_{9}, \mathrm{Gi}_{0}, \mathrm{Q}_{4}, \mathrm{M}_{6}, \mathrm{Sm}_{51}, \mathrm{MVI}_{0}, \mathrm{HIV}_{0}$ \\
Mixed & ${ }^{*} \mathrm{~K}_{42}, \mathrm{Ge}_{5}, \mathrm{Gi}_{0}, \mathrm{Q}_{5}, \mathrm{M}_{31}, \mathrm{Sm}_{0}, \mathrm{MVI}_{7}, \mathrm{HIV}_{10}$ \\
& Nano & ${ }^{*} \mathrm{~K}_{46}, \mathrm{Ge}_{7}, \mathrm{Gi}_{0}, \mathrm{Q}_{3}, \mathrm{M}_{30}, \mathrm{Sm}_{0}, \mathrm{MVI}_{7}, \mathrm{HIV}_{7}$ \\
Kaolinitic & Macro & ${ }^{*} \mathrm{~K}_{52}, \mathrm{Ge}_{12}, \mathrm{Gi}_{5}, \mathrm{Q}_{4}, \mathrm{M}_{3}, \mathrm{Sm}_{0}, \mathrm{MVI}_{0}, \mathrm{HIV}_{24}$ \\
& Nano & ${ }^{*} \mathrm{~K}_{55}, \mathrm{Ge}_{15}, \mathrm{Gi}_{6}, \mathrm{Q}_{2}, \mathrm{M}_{3}, \mathrm{Sm}_{0}, \mathrm{MVI}_{0}, \mathrm{HIV}_{19}$ \\
Biosolid & Macro & ${ }^{*} \mathrm{ND}$ \\
& Nano & \\
\hline
\end{tabular}

${ }^{*} \mathrm{~K}$ = Kaolinite, Ge = Goethite, Gi = Gibbsite, Q = Quartz, M = Mica, Sm = Smectite, MVI = Mica-Vermiculite Interstratified, HIV = Hydroxyinterlayered Vermiculite, ND $=$ Not Detected.

Table 3). One confounding observation is that there are higher quantities of flocculating agents (Fe and $\mathrm{Al}$ hydroxides, goethite, and gibbsite) in the NCs, yet they remain more stable than their corresponding MCs (Table 3, Figure 1). The answer to this dilemma may lie in the EDS data which indicated greater ( $\mathrm{Al}+\mathrm{Fe})$ :Si ratios in the NCs than in their corresponding MCs. Increased (Al + Fe):Si ratios have shown to enhance humic acid sorption capacities and stabilize colloid suspensions [16] [29].

\subsubsection{Effects of Particle Morphology}

The smectitic MCs showed typical montmorillonitic honeycomb shapes with edge-face interactions (Table 1). Montmorillonite can be more dispersive than other minerals because weak Van der Waals' forces between oriented tactoids allow penetration between layers by water and exchangeable cations, which may inhibit stable aggregate formation [9]. The smectitic NCs indicated less particle to particle attachment than the MCs (Table 1). Morphologies displayed by the mixed mineralogy MCs showed tightly aggregated honeycomb-like plates, while the mixed NCs had various shapes encompassing tubes, rods, plates and hexagons within a tightly aggregated mineral matrix (Table 1). The greater morphological variation in the shapes of the mixed NCs in TEM images may indicate some surface deformation (Table 1). Similar HIV images were shown with associated iron minerals [21]. Kaolinitic MC SEM images had the typical hexagonal shapes displayed by kaolinitic minerals, while TEM images of the NCs showed much smaller hexagonal shapes with a noted increase in iron minerals embedded within and binding the hexagonal aggregates (Table 1) [22]. Kaolinitic minerals tend to flocculate below pH 7, which is representative of the colloid suspension $\mathrm{pH}$ range [9] (Table 4).

The morphological compositions of the biosolid MCs, as shown in their SEM images, displayed various aggregations of organic materials with some quartz grains present, while the NC TEM images lacked distinct particle shapes or displays of individual particle morphology, indicating less integrity of sample and potential dissolution (Table 1). Overall, within the mineral colloids, SEM images displayed more tightly held aggregates within the MCs (Table 1), indicating greater flocculation potential (Figure 1) as opposed to the more loosely held aggregates displayed by their corresponding NCs in TEM images (Table 1).

Additionally, TEM images suggested potential particle morphology alterations from surface disorder, which may have modified NC stability behavior (Table 1). TEM images of the smectitic and mixed NC showed similar disorder and potential structural abnormalities (Table 1), with particles adhering to each other to display extended and oblong morphologies. The cause of such abnormalities has been suggested to be impurities or oriented aggregation resulting from forced structural incorporation of previously sorbed species that could alter surface sites and influence stability and reactivity characteristics [5] [30]-[32].

\subsubsection{Surface Area Effects}

With the exception of the biosolids, NCs had greater surface area than the MCs despite the SEM indications of nanoparticle adhesion to MC surfaces (Table 1) [5] [6] [30]. Surface area showed trends by composition, with the largest coming from the biosolid materials, followed by the smectitic, mixed, and kaolinitic colloids, respectively (Table 1). In addition to size effects, increased surface area values measured in the NCs could be the result of organic surface coatings or the presence of iron hydroxides maximizing sorption of the EGME [33] [34]. 
The larger surface areas in the NCs also indicate greater potential for contaminant sorption and increased repulsion of similarly charged particles, thus enhancing stability potentials.

\subsubsection{Effect of Chemical Characteristics}

Unadjusted $\mathrm{pH}$ values ranged from 4.9 to 5.4 for both the NC and MC fractions (Table 4). Such a narrow pH range evinces that $\mathrm{pH}$ values may not have promoted differences in stability between the differing colloid compositions or sizes, but may have contributed to a greater overall flocculation tendency (Table 4, Figure 1) [2]. However, in spite of this narrow $\mathrm{pH}$ range, there were significant differences in stabilization potentials (Figure 1) across most of the studied colloid fractions. The same colloids in higher $\mathrm{pH}$ environments would likely be even more dispersive, as evidenced by the zeta potential titrations above $\mathrm{pH} 6$ (Figure 3).

The electrical conductivity (EC) and ionic strength (IS) of the colloids were relatively low with the NCs showing higher overall values than their corresponding MCs (Table 4). Additionally, the bio-colloids had greater EC and ionic strength values than most mineral colloids except for the mixed NCs (Table 4). Higher ionic strength values for the NCs could decrease stability [35] and may have contributed to lower fractional recoveries as compared to MCs (Table 1 and Table 4). However, at the natural range these higher EC and ionic strength values of the NC suspensions did not appear to significantly deter the overall stability of the NCs as shown in Figure 1. Increased ionic strength effects from contaminant additions resulted in lower NC and MC stability, likely due to flocculation in the presence of contaminants, with greater flocculation at higher contaminant concentrations (Figure 1) [6] [16]. Increased ionic strength has been shown to reduce the effectiveness of Coulomb repulsion by shielding the charge of two approaching particles [6]. This effect on Coulomb repulsion may explain the stability findings after contaminant additions of $10 \mathrm{mg} \cdot \mathrm{L}^{-1}$, where significantly lower colloid suspension concentrations indicated flocculation in all but the bio-NC fractions (Figure 1). Coulomb repulsions appeared to overcome ionic strength effects at $2 \mathrm{mg} \cdot \mathrm{L}^{-1}$ contaminant concentrations.

The higher SAR values of the NCs over that of the MCs are more consistent with their stability trends than the IS values, indicating greater dispersion potentials in the NCs over their corresponding MCs (Table 4). The higher CEC values of the NCs over the MCs are also complimentary to their larger and likely more reactive surface areas (Table 4). As expected, the smectitic colloids had the greatest CEC within the mineral colloids, followed by the mixed mineralogy and kaolinitic colloids (Table 4). The higher OC content of the bio-colloids

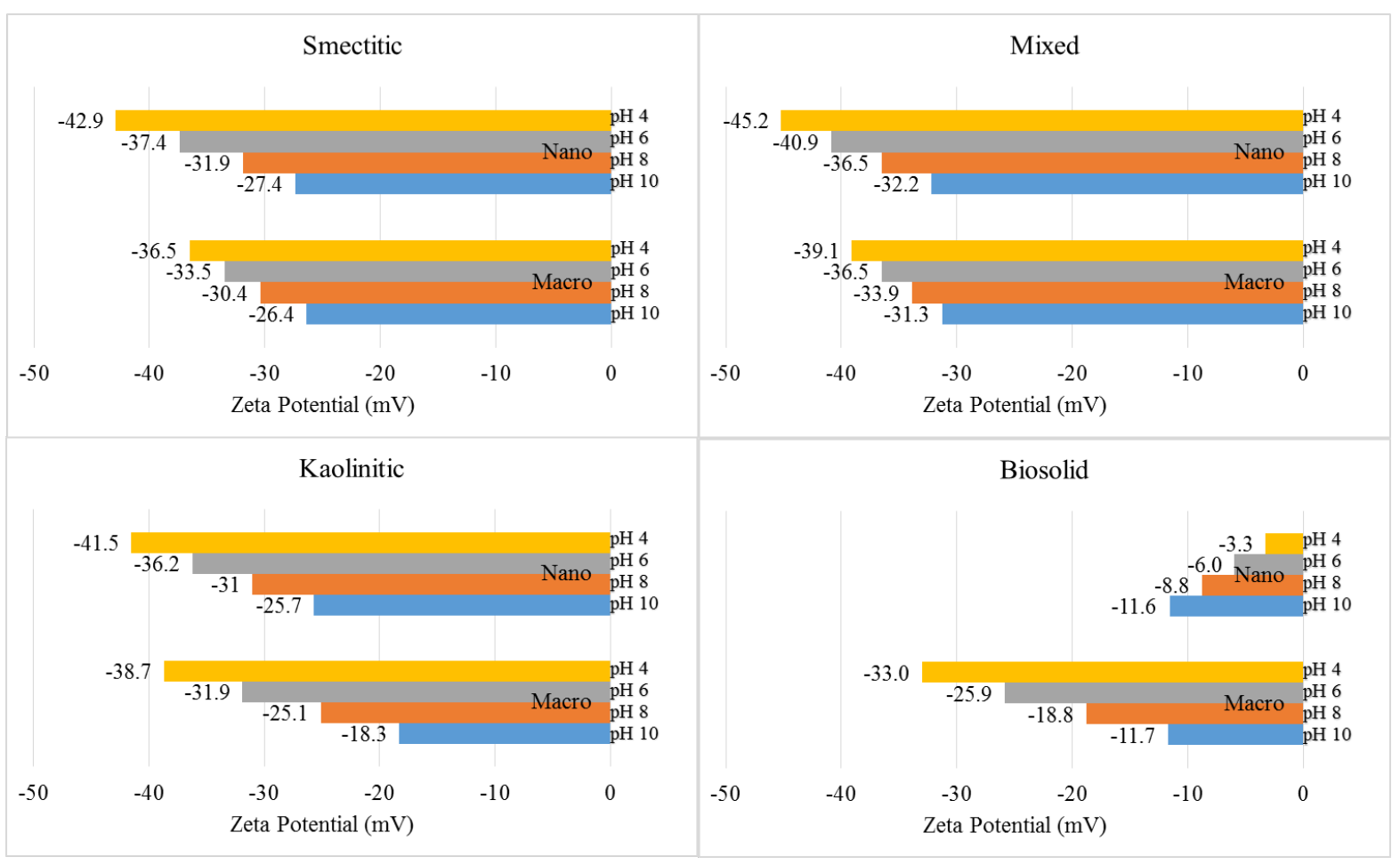

Figure 3. Zeta potential of nanocolloid and macrocolloid fractions at pH 4, 6, 8, and 10. 
Table 4. Selected chemical characteristics of the macro- and nano-colloid fractions.

\begin{tabular}{|c|c|c|c|c|c|c|c|c|c|c|c|}
\hline Properties & $\begin{array}{l}\text { Size } \\
\text { Class }\end{array}$ & $\begin{array}{c}\text { Electrical } \\
\text { Conductivity } \\
\left(\text { mmhos } \mathrm{cm}^{-1}\right)\end{array}$ & $\begin{array}{l}\text { Ionic } \\
\text { Strength } \\
\left(\mathrm{mol} \cdot \mathrm{L}^{-1}\right)\end{array}$ & $\begin{array}{c}\text { Natural } \\
\text { pH }\end{array}$ & $\begin{array}{c}\mathrm{CEC}^{\#} \\
\left(\mathrm{cmol}_{\mathrm{c}} \cdot \mathrm{kg}^{-1}\right) \\
\pm \mathrm{SD}^{\mp}\end{array}$ & $\begin{array}{c}\mathrm{Ca}^{2+} \\
\left(\mathrm{cmol}_{\mathrm{c}} \cdot \mathrm{kg}^{-1}\right)\end{array}$ & $\begin{array}{c}\mathrm{Mg}^{2+} \\
\left(\mathrm{cmol}_{\mathrm{c}} \cdot \mathrm{kg}^{-1}\right)\end{array}$ & $\begin{array}{c}\mathrm{K}^{+} \\
\left(\mathrm{cmol}_{\mathrm{c}} \cdot \mathrm{kg}^{-1}\right)\end{array}$ & $\begin{array}{c}\mathrm{Na}^{+} \\
\left(\mathrm{cmol}_{\mathrm{c}} \cdot \mathrm{kg}^{-1}\right)\end{array}$ & $\mathrm{SAR}^{+\dagger}$ & $\begin{array}{c}\mathrm{OC} \\
\left(\mathrm{mg} \cdot \mathrm{kg}^{-1}\right)^{\ddagger}\end{array}$ \\
\hline \multirow{2}{*}{ Smectitic } & Macro & $3.93 \times 10^{-3}$ & $4.99 \times 10^{-5}$ & 4.92 & $35.05 \pm 12.84$ & 27.60 & 6.27 & 0.57 & 0.61 & 0.15 & 658 \\
\hline & Nano & $6.07 \times 10^{-3}$ & $7.71 \times 10^{-5}$ & 5.12 & $42.19 \pm 15.12$ & 32.64 & 8.00 & 0.78 & 0.77 & 0.17 & 897 \\
\hline \multirow{2}{*}{ Mixed } & Macro & $2.91 \times 10^{-3}$ & $3.70 \times 10^{-5}$ & 5.07 & $8.89 \pm 1.62$ & 3.80 & 3.40 & 1.15 & 0.54 & 0.28 & 645 \\
\hline & Nano & $3.09 \times 10^{-2}$ & $3.92 \times 10^{-4}$ & 4.92 & $10.51 \pm 1.67$ & 4.00 & 3.47 & 2.80 & 0.24 & 0.12 & 774 \\
\hline \multirow{2}{*}{ Kaolinitic } & Macro & $2.87 \times 10^{-3}$ & $3.64 \times 10^{-5}$ & 4.91 & $6.94 \pm 1.85$ & 4.40 & 1.60 & 0.45 & 0.49 & 0.28 & 430 \\
\hline & Nano & $3.80 \times 10^{-3}$ & $4.83 \times 10^{-5}$ & 5.38 & $13.12 \pm 2.84$ & 7.12 & 3.73 & 1.23 & 1.04 & 0.45 & 647 \\
\hline \multirow{2}{*}{ Biosolid } & Macro & $1.56 \times 10^{-2}$ & $1.97 \times 10^{-4}$ & 5.39 & $37.61 \pm 14.85$ & 31.60 & 3.60 & 1.64 & 0.77 & 0.18 & $1.3 \mathrm{~K}$ \\
\hline & Nano & $4.69 \times 10^{-2}$ & $5.96 \times 10^{-4}$ & 5.25 & $70.99 \pm 22.98$ & 51.68 & 12.13 & 3.98 & 3.20 & 0.57 & $16 \mathrm{~K}$ \\
\hline
\end{tabular}

${ }^{\ddagger} \mathrm{SD}=$ Standard Deviation from duplicate or triplicate measurements. ${ }^{\S}$ Ionic Strength (IS) = Estimated using Griffin and Jurinak’s equation where IS (mol $\cdot \mathrm{L}^{-1}$ ) $=0.0127 \times$ Electrical Conductivity (millimhos $\cdot \mathrm{cm}^{-1}$ ) $(1973) .{ }^{\#} \mathrm{CEC}=$ Cation Exchange Capacity by sum of cations. ${ }^{\dagger \dagger} \mathrm{SAR}=\mathrm{Sodium}$ Adsorption Ratio. ${ }^{\ddagger \ddagger}$ OC $=$ Organic Carbon (Total Carbon-Dissolved Organic Carbon).

may have contributed to their higher CEC over that of the mineral colloids (Table 4).There were higher exchangeable $\mathrm{Ca}^{2+}$ and $\mathrm{Mg}^{2+}$ concentrations in the NCs than the corresponding MC fractions (Table 4). Divalent cations can promote flocculation and may explain why NCs were found attached to MC surfaces likely due to bridging effects (Table 1 and Table 4) [16].

NCs also contained higher OC content than their corresponding MCs which may have enhanced their stability over corresponding MCs (Figure 1, Table 4) [2] [8] [26]. While some studies indicated enhanced dispersibility and stability with increased OC content due to both charge and stearic stabilization [4] [16] [26] [27] [36], other findings suggested weak correlations [1]. It is likely, that the presence of differing OC functional groups caused a different behavior. Referring back to the $d_{h}$ findings (Figure 2), the greatest aggregation potentials with contaminant additions occurred in the biosolid colloids that had a combination of greater OC content and surface area (Table 1 and Table 4). Correlations between amount of $\mathrm{C}$ measured per unit surface area (SA) showed that the greatest aggregation potentials occurred in the colloids with the highest C:SA ratios (kaolinitic and biosolid NCs, respectively) (Figure 2, Table 1 and Table 4). The difference in OC functional group as well as C:SA ratio may also explain differences in stability findings (Table 1 and Table 4; Figure 1). It is also possible that OC bridges together micro-nano-aggregates that are more stable in suspension than individual particles. Despite higher OC and potential formations of micro-nano-aggregates, NCs were generally still more stable in the absence and presence of contaminants than were MCs (Figure 1).

\subsubsection{Zeta Potential Effects}

NC zeta potentials were more negative than that of their corresponding MCs, with both sizes showing increasingly negative zeta potentials with increased $\mathrm{pH}$ (Figure 3). Mineral NCs exhibited more negative zeta potentials than their corresponding MC counterparts and the bio-colloids, especially above $\mathrm{pH} 6$ (Figure 3). Based on the assumption that zeta potentials approximate the charge residing in the diffuse layer of the electrical double layer, the negative zeta potential values suggest that all colloids bear a net negative surface charge. The increased negative charge with increasing $\mathrm{pH}$ is ascribed to the deprotonation of phyllosilicate edge sites, and indicates repulsion energies of the particles, suggesting increased stability potential of NCs over corresponding MCs (Figure 3), especially in negatively charged subsurface environments [37].

In the mineral colloids, there was never a point where the zeta potential reached zero (Figure 3), suggesting isoelectric points (the $\mathrm{pH}$ of zero mobility) of $<4$ for all colloids [38]. This was especially surprising in fractions where mineral compositions were dominated by kaolinite, which has an isoelectric point of 4.25 [38]. Apparently, the presence of other minerals and organic carbon surface coatings have considerably altered the isoelectric behavior of the mineral colloids [39].

The biosolid colloids had differing trends from the mineral colloids, where the bio-NCs became less negative with increasing $\mathrm{pH}$ as opposed to bio-MCs that showed an increased negative charge with increasing $\mathrm{pH}$ 
(Figure 3). This may suggest a lower stability potential in the bio-NCs than in the bio-MCs, which is the opposite of what was seen in stability kinetics experiments (Figure 1). The less negative zeta potentials exhibited by the bio-colloids than the mineral colloids may be due to the greater ionic strength of the bio-colloids, especially those of the bio-NCs (Table 3), whose higher ionic strength likely overwhelmed potential negative surface charges generated by carboxyl groups above pH's 2.5 and 6 [38].

In the single point zeta potential measurements, additions of 2 and $10 \mathrm{mg} \cdot \mathrm{L}^{-1}$ mixed contaminants resulted in NC zeta potentials which were still more negative than those of their corresponding MCs, with both sizes showing trends based on composition (Figure 4). This display of greater stability in the NCs over the MCs complements the stability kinetics studies, suggesting that their stabilization potentials overcame their supposed high surface energy, even in the presence of up to $2 \mathrm{mg} \cdot \mathrm{L}^{-1}$ contaminants [6]. It is noted here that in order to mimic natural conditions, the $\mathrm{pH}$ of the zeta potential measurements varied, so the change in zeta potential is likely a reference to colloidal stability potential (Figure 3 and Figure 4). Overall, the mineral colloids indicated greater stability over bio-colloids through higher negative zeta potentials in the presence of 0,2 and even $10 \mathrm{mg} \cdot \mathrm{L}^{-1}$ contaminant concentrations, although evidence of flocculation was more prevalent after $10 \mathrm{mg} \cdot \mathrm{L}^{-1}$ contaminant additions (Figure 1 and Figure 4). While some aggregation was implied with increasing ionic strengths of contaminants by slight shifts towards less negative zeta potentials (Figure 4), corresponding to increased $\mathrm{d}_{\mathrm{h}}$ values in the presence of contaminants (Figure 2), the NCs indicated significantly greater stability potentials over their corresponding MCs (Figure 1). Colloids with the most negative zeta potential usually have the largest resistance to flocculation [16], which was true for the smectitic, mixed, kaolinitic and biosolid NCs in the absence and presence of 2 and $10 \mathrm{mg} \cdot \mathrm{L}^{-1}$ contaminants (Figure 3). The MCs did not show the same stability trends based on composition, and surprisingly, the smectitic MCs were the least stable upon contaminant additions as compared to the other mineral (and even the biosolid) MCs (Figure 1 and Figure 4). The lack of stability indicated by lower negative zeta potentials in the smectitic MCs upon addition of contaminants (despite their higher initial zeta potential) may be a function of their smaller C:SA ratio (Table 1 and Table 4). The greater shifts in their zeta potentials (v27 $\mathrm{mV}$ without contaminants shifting to -18 , then $-11 \mathrm{mV}$ with 2 and $10 \mathrm{mg} \cdot \mathrm{L}^{-1}$ contaminant additions, respectively) were most likely materialized by greater cation contaminant attraction to their high initial negative charge and to larger surface area availability (Table 1, Figure 4). Despite this large shift in the smectitic MC zeta potential, the stability kinetics studies indicated that smectitic MCs were more stable than any of the other mineral and biosolid MCs (Figure 1). The disparity of the zeta potential data to that of the stability kinetics data suggests that while the zeta potentials are consistent in predicting colloid stability of minerals versus biosolids, they maybe inconsistent in predicting stability trends based on mineralogy.

The implications may be that colloid stability may not be accurately predicted from zeta potential and $d_{h}$ measurements in the presence of contaminants. Also, it emphasizes placing more weight on stability settling experiments than chemical data alone for transport predictions (although chemical characterization should still be considered important for explaining portions of the overall model). Finally, this showcases how irrelevant the average surface charge of colloids may become in contaminant transport behavior because of spatial heterogeneity and the importance of considering additional multiple relevant factors to achieve reliable assessments of environmental risks [17].

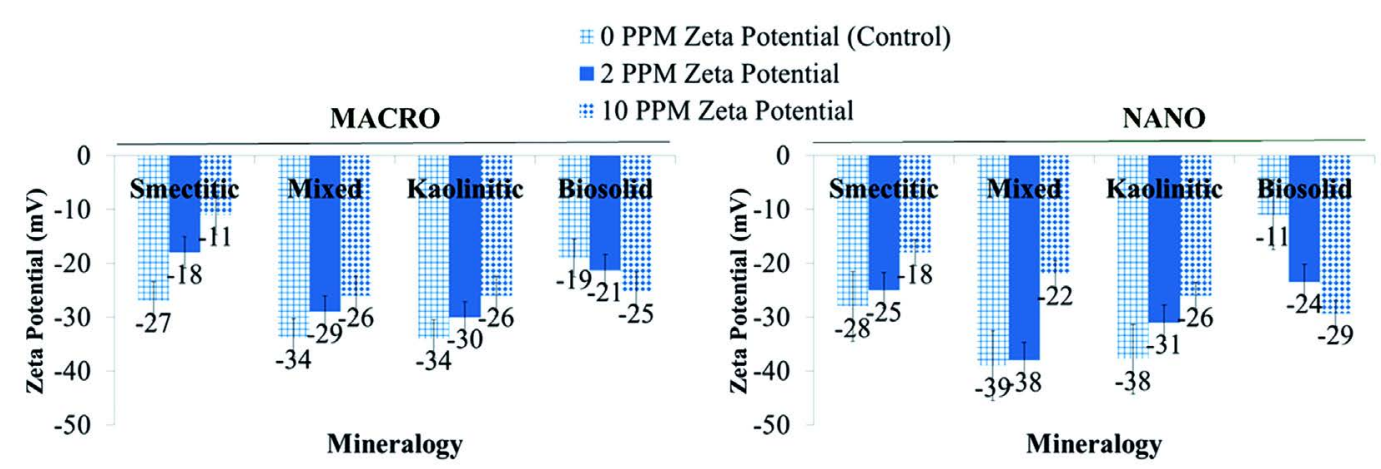

Figure 4. Zeta potential of macrocolloids and nanocolloids in mixtures with equal parts $\left(0,2\right.$, and $\left.10 \mathrm{mg} \cdot \mathrm{L}^{-1}\right)$ of each contaminant ( $\mathrm{As}, \mathrm{Se}, \mathrm{Cu}$ and $\mathrm{Pb}$ ) (error bars represent standard error of triplicate measurements on duplicate samples). 


\section{Conclusion}

This study filled a previous void on the stability behavior of natural soil and biosolid water dispersible NCs and their differences from their corresponding larger MC fractions. The findings demonstrated that soil and biosolid NCs are more stable in the absence and presence of up to $2 \mathrm{mg} \cdot \mathrm{L}^{-1} \mathrm{As}$, Se, $\mathrm{Cu}$ and $\mathrm{Pb}$ contaminants than corresponding MCs. Only the bio-NCs showed considerable stability at higher contaminant loads. The importance of mineralogy in stability was best shown by the MCs, where the smectitic and mixed colloids were more stable than the kaolinitic and biosolid compositions. In the NCs, the mineral colloids were more stable than the bio-colloids. Kaolinitic NCs and MCs showed surprisingly high stability potentials, even in the presence of goethite and gibbsite minerals, likely due to stearic stabilization effects of surface OC functional groups. Overall, NCs, regardless of mineralogy, where shown to have as much as $20 \%$ more colloids in suspension after 48 hours in the absence and presence of $\mathrm{As}, \mathrm{Se}, \mathrm{Cu}$ and $\mathrm{Pb}$ contaminants. While size played a very important role in the colloid stability behavior, NCs were also found to enhance aggregation of MCs via attachment to their surfaces. Further study is needed to better understand the causes of this nano-mediated aggregation behavior, but the presence of OC surface coatings and increased $\mathrm{Al} / \mathrm{Fe}: \mathrm{Si}$ ratios of NCs may have contributed to MC coagulation. Overall, the findings of this investigation demonstrated that soil NCs through a combination of physical, chemical, mineralogical and morphological properties that contribute to enhanced stability in natural environments, possess a higher potential to transport contaminants to greater distances than their corresponding larger size MC fractions. This potential was even greater with the bio-nano-colloids at higher contaminant loads. However, coagulation phenomena through nano-macro-colloid interactions may complicate their behavior in natural environments and result in misleading predictions. Therefore, multiple physicochemical and mineralogical parameters need to be considered in contaminant transport models in order to accurately assess environmental pollution risks and develop efficient remediation strategies.

\section{References}

[1] Seta, A.K. and Karathanasis, A.D. (1996) Water Dispersible Colloids and Factors Influencing Their Dispersibility from Soil Aggregates. Geoderma, 74, 255-266. http://dx.doi.org/10.1016/S0016-7061(96)00066-3

[2] Seta, A.K. and Karathanasis, A.D. (1997) Stability and Transportability of Water-Dispersible Soil Colloids. Soil Science Society of America Journal, 61, 604-611. http://dx.doi.org/10.2136/sssaj1997.03615995006100020033x

[3] IUPAC (McNaught, A.D. and Wilkinson, A., Eds.) (1997) IUPAC Compendium of Chemical Terminology. 2nd Edition, Blackwell Science Publications, Oxford.

[4] Christian, P., Von der Kammer, F., Baalousha, M. and Hofmann, T. (2008) Nanoparticles: Structure, Properties, Preparation and Behaviour in Environmental Media. Ecotoxicology, 17, 326-343. http://dx.doi.org/10.1007/s10646-008-0213-1

[5] Maurice, P.A. and Hochella Jr., M.F. (2008) Nanoscale Particles and Processes: A New Dimension in Soil Science. Advances in Agronomy, 100, 123-153. http://dx.doi.org/10.1016/S0065-2113(08)00605-6

[6] Karathanasis, A.D. (2010) Composition and Transport Behavior of Soil Nanocolloids in Natural Porous Media. In: Frimmel, F.H. and NieBner, R., Eds., Nanoparticles in the Water Cycle, Springer-Verlag, Berlin, Heidelberg, Ch. 4.

[7] Bradford, S.A. and Torkzaban, S. (2008) Colloid Transport and Retention in Unsaturated Porous Media: A Review of Interface-, Collector-, and Pore-Scale Processes and Models. Vadose Zone Journal, 7, 667-681. http://dx.doi.org/10.2136/vzj2007.0092

[8] Kretzschmar, R., Borkovec, M., Grolimund, D. and Elimelech, M. (1999) Mobile Subsurface Colloids and Their Role in Contaminant Transport. Advances in Agronomy, 66, 121-194. http://dx.doi.org/10.1016/S0065-2113(08)60427-7

[9] Lado, M. and Ben-Hur, M. (2004) Soil Mineralogy Effects on Seal Formation, Runoff and Soil Loss. Applied Clay Science, 24, 209-224. http://dx.doi.org/10.1016/j.clay.2003.03.002

[10] Tsao, T.M., Chen, Y.M. and Wang, M.K. (2011) Origin, Separation, and Identification of Environmental Nanoparticles: A Review. Journal of Environmental Monitoring, 13, 1156-1163. http://dx.doi.org/10.1039/c1em10013k

[11] Kaplan, D.I., Bertsch, P.M. and Adriano, D.C. (1997) Mineralogical and Physicochemical Differences between Mobile and Nonmobile Colloidal Phases in Reconstructed Pedons. Soil Science Society of America Journal, 61, 641-649. http://dx.doi.org/10.2136/sssaj1997.03615995006100020038x

[12] Ouyang, Y., Shinde, D., Mansell, R.S. and Harris, W. (1996) Colloid-Enhanced Transport of Chemicals in Subsurface Environments: A Review. Critical Reviews in Environmental Science and Technology, 26, 189-204. http://dx.doi.org/10.1080/10643389609388490 
[13] Grund, S.C., Hanusch, K. and Wolf, H.U. (2005) Arsenic and Arsenic Compounds. In: Ullmann's Encyclopedia of Industrial Chemistry, Wiley-VCH, Weinheim. http://dx.doi.org/10.1002/14356007.a03_113.pub2

[14] Su, C. and Suarez, D.L. (2000) Selenate and Selenite Sorption on Iron Oxides: An Infrared and Electrophoretic Study. Soil Science Society of America Journal, 64, 101-111. http://dx.doi.org/10.2136/sssaj2000.641101x

[15] Signes-Pastor, A., Burlo, F., Mitra, K. and Carbonell-Barrachina, A.A. (2007) Arsenic Biogeochemistry as Affected by Phosphorus Fertilizer Addition, Redox Potential and pH in a West Bengal (India) Soil. Geoderma, 137, 504-510. http://dx.doi.org/10.1016/j.geoderma.2006.10.012

[16] Kjaergaard, C., Hansen, H.C.B., Koch, C.B. and Villholth, K.G. (2004) Properties of Water-Dispersible Colloids from Macropore Deposits and Bulk Horizons of an Agrudalf. Soil Science Society of America Journal, 68, 1844-1852. http://dx.doi.org/10.2136/sssaj2004.1844

[17] McCarthy, J.F. and McKay, L.D. (2004) Colloid Transport in the Subsurface: Past, Present and Future Challenges. Vadose Zone Journal, 3, 326-337.

[18] Karathanasis, A.D., Johnson, D.M.C. and Matocha, C.J. (2005) Biosolid Colloid-Mediated Transport of Copper, Zinc, and Lead in Waste-Amended Soils. Journal of Environmental Quality, 34, 1153-1164. http://dx.doi.org/10.2134/jeq2004.0403

[19] Karathanasis, A.D. and Johnson, D.M.C. (2006) Subsurface Transport of Cd, Cr and Mo Mediated by Biosolid Colloids. Science of the Total Environment, 354, 157-169. http://dx.doi.org/10.1016/j.scitotenv.2005.01.025

[20] Karathanasis, A.D. and Johnson, D.M.C. (2006) Stability and Transportability of Biosolid Colloids through Undisturbed Soil Monoliths. Geoderma, 130, 334-345. http://dx.doi.org/10.1016/j.geoderma.2005.02.006

[21] Németh, T., Jiménez-Millán, J., Sipos, P., Abad, I., Jiménez-Espinosa, R. and Szalai, Z. (2011) Effect of Pedogenic Clay Minerals on the Sorption of Copper in a Luvisol B Horizon. Geoderma, 160, 509-516. http://dx.doi.org/10.1016/j.geoderma.2010.09.031

[22] Zhu, R. and Lu, S. (2010) A High-Resolution TEM Investigation of Nanoparticles in Soils. In: Molecular Environmental Soil Science at the Interfaces in the Earth's Critical Zone, Session 4, Springer, Berlin, 282-284.

[23] Goldstein, J.I., Newbury, D.E., Echlin, P., Joy, D.C., Fiori, C., Lifshin, E., et al. (1992) Scanning Electron Microscopy and X-Ray Microanalysis. 2nd Edition, Plenum Press, New York, 820p. http://dx.doi.org/10.1007/978-1-4613-0491-3

[24] Karathanasis, A.D. (2008) Thermal Analysis of Soil Minerals. In: Ulery, A.L. and Drees, L.R., Eds., Methods of Soil Analysis, Part 5, Mineralogical Methods, Chapter 5, Soil Science Society of America, Madison, 117-160, http://dx.doi.org/10.2136/sssabookser5.5.c5

[25] Griffin, R.A. and Jurinak, J.J. (1973) Estimation of Activity Coefficients from the Electrical Conductivity of Natural Aquatic Systems and Soil Extracts. Soil Science, 116, 26-30. http://dx.doi.org/10.1097/00010694-197307000-00005

[26] Kaplan, D.I., Bertsch, P.M., Adriano, D.C. and Miller, W.P. (1993) Soil-Borne Mobile Colloids as Influenced by Water Flow and Organic Carbon. Environmental Science \& Technology, 27, 1192-1200. http://dx.doi.org/10.1021/es00043a021

[27] Ottofuelling, S., Von der Kammer, F. and Hofmann, T. (2011) Commercial Titanium Dioxide Nanoparticles in both Natural and Synthetic Water: Comprehensive Multidimensional Testing and Prediction of Aggregation Behavior. Environmental Science \& Technology, 45, 10045-10052. http://dx.doi.org/10.1021/es2023225

[28] Goldberg, S. and Glaubig, R.A. (1987) Effect of Saturating Cation, pH, and Aluminum and Iron Oxides on the Flocculation of Kaolinite and Montmorillonite. Clays and Clay Mineral, 35, 220-227. http://dx.doi.org/10.1346/CCMN.1987.0350308

[29] Shen, Y.H. (1999) Sorption of Humic Acid to Soil: The Role of Mineralogical Composition. Chemosphere, 38, 24892499. http://dx.doi.org/10.1016/S0045-6535(98)00455-X

[30] Waychunas, G.A., Kim, C.S. and Banfield, J.A. (2005) Nanoparticulate Iron Oxide Minerals in Soils and Sediments: Unique Properties and Contaminant Scavenging Mechanisms. Journal of Nanoparticle Research, 7, 409-433. http://dx.doi.org/10.1007/s11051-005-6931-X

[31] Gilbert, B., Huang, F., Zhang, H., Waychunas, G.A. and Banfield, J.F. (2004) Nanoparticles: Strained and Stiff. Science, 305, 651-654. http://dx.doi.org/10.1126/science.1098454

[32] Qu, F., Oliveira, R.H. and Morais, P.C. (2004) Effects of Nanocrystal Shape on the Surface Charge Density of Ionic Colloidal Nanoparticles. Journal of Magnetism and Magnetic Materials, 272-276, 1668-1669. http://dx.doi.org/10.1016/j.jmmm.2003.12.1076

[33] Pennell, K.D., Boyd, S.A. and Abriola, L.M. (1995) Surface Area of Soil Organic Matter Reexamined. Soil Science Society of America Journal, 59, 1012-1018. http://dx.doi.org/10.2136/sssaj1995.03615995005900040008x

[34] Schwertmann, U. and Taylor, R.M. (1989) Iron Oxides. In: Dixon, J.B. and Weeds, S.B., Eds., Minerals in Soil Envi- 
ronments, 2nd Edition, Soil Science Society of America, Madison, 145-180.

[35] Hesterberg, D. and Page, A.L. (1990) Flocculation Series Test Yielding Time-Invariant Critical Coagulation Concentrations of Sodium Illite. Soil Science Society of America Journal, 54, 729-735. http://dx.doi.org/10.2136/sssaj1990.03615995005400030017x

[36] Hassellöv, M. and Von der Kammer, F. (2008) Iron Oxides as Geochemical Nanovectors for Metal Transport in SoilRiver Systems. Elements, 4, 401-406. http://dx.doi.org/10.2113/gselements.4.6.401

[37] McCarthy, J.F. and Zachara, J.M. (1989) Subsurface Transport of Contaminants. Environmental Science \& Technology, 23, 496-502.

[38] Essington, M.E. (2004) Soil and Water Chemistry: An Integrative Approach. CRC Press LLC, Boca Raton.

[39] Bertsch, P.M. and Seaman, J.C. (1999) Characterization of Complex Mineral Assemblages: Implications for Contaminant Transport and Environmental Remediation. Proceedings of the National Academy of Sciences of the United States of America, 96, 3350-3357. http://dx.doi.org/10.1073/pnas.96.7.3350 
Scientific Research Publishing (SCIRP) is one of the largest Open Access journal publishers. It is currently publishing more than 200 open access, online, peer-reviewed journals covering a wide range of academic disciplines. SCIRP serves the worldwide academic communities and contributes to the progress and application of science with its publication.

Other selected journals from SCIRP are listed as below. Submit your manuscript to us via either submit@scirp.org or Online Submission Portal.
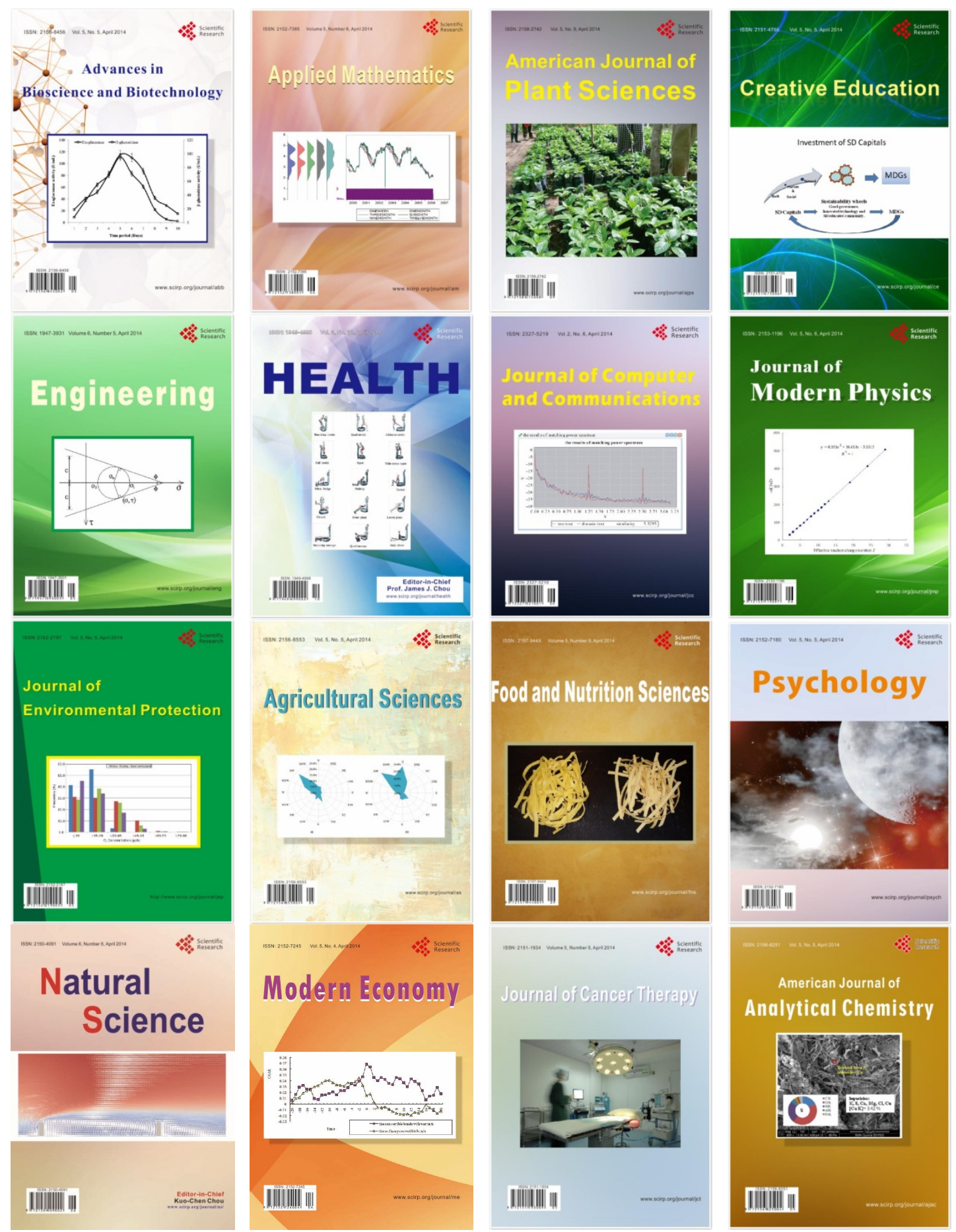